\title{
FAVELAS E A PANDEMIA DE COVID-19, UMA TRAGÉDIA ANUNCIADA?
}

\author{
ELISA DE CARVALHO ${ }^{1}$
}

1 Doutoranda em Planejamento e Governança Pública - UTFPR, Curitiba/Paraná. lisacris@gmail.com.

\section{RESUMO}

Grotão, ocupação, vila, alagado, invasão, comunidade... Falar de favelas é um tema complexo que acende muitas discussões sobre políticas de urbanização, infraestrutura e identidade. Resultado de um crescimento urbano descontrolável, de uma urbanização excludente e de uma industrialização altamente exploradora, sulcadas na paisagem, elas já são parte do cenário urbano em boa parte das metrópoles mundiais. Estudos estimam que, até 2030, uma em cada 4 pessoas morará em assentamentos chamados de informais: áreas construídas com grupos de unidades habitacionais dos quais os ocupantes não têm direito legal ou os ocupam ilegalmente; assentamentos não planejados e áreas onde as habitações não estão em conformidade com os regulamentos atuais de planejamento e construção (habitação não autorizada) $(\mathrm{OECD}, 2001)$. A história da moradia no Brasil se confunde com o surgimento das favelas, repleta de estereótipos e historicamente criminalizada. Em 2020, a história se repete ou se inverte, estigmatizado reduto das epidemias e doenças, as comunidades cariocas lutam para que a COVID-19 não "suba o morro", pois, ironicamente, a pandemia está no asfalto.

Palavras-chave: COVID-19; Favelas; Habitação; Políticas Habitacionais.

\section{SLUMS AND COVID-19, CHRONICLE OF A TRAGEDY FORETOLD}

\begin{abstract}
Ghettos, barrios, low neighborhoods, poverty-stricken communities...Talking about slums is a complex topic that sparks many discussions about urbanization policies, infrastructure and identity. The result of uncontrollable urban growth, exclusionary urbanization and highly exploitative industrialization, furrowed into the landscape, they are already part of the urban scenario in much communities of the world's metropolises. Studies estimate that by 2030, one in four people will live in so-called informal settlements: areas where groups of housing units built on land that the occupants have no legal rights to or occupy illegally; unplanned settlements and areas where housing does not comply with current planning and construction regulations (unauthorized housing) (OECD, 2001). The history of housing in Brazil merges with the emergence of favelas, full of stereotypes and historically criminalized. In 2020, history repeats or reverses itself, stigmatized as a stronghold of epidemics and diseases, Carioca communities struggle so that COVID-19 does not "climb the hill", because, ironically, the pandemic is on the asphalt.
\end{abstract}

Keywords: COVID-19; Housing; Housing Policies; Slums.

\section{INTRODUÇÃO}

Recebido em 15/06/2020 e aprovado para publicação em 05/02/2021. 
A pandemia do COVID-19 evoca o debate em torno da situação das favelas. Marginalizadas e estigmatizadas, as comunidades sempre foram consideradas redutos de epidemias e doenças de origem sanitária. Em 1930, o Plano do Urbanista Agache, que visava remodelar a cidade do Rio de Janeiro, denunciava o perigo para a saúde pública e para a ordem social que a permanência das favelas representava (VALLADARES, 2000).

A ideia de extermínio das favelas carrega consigo uma premissa que nega a essas pessoas o direito à cidade, já que esses aglomerados urbanos não deviam estar ali. $\mathrm{O}$ direito à cidade, no contexto legal brasileiro, é garantido pelo Estatuto da Cidade de 2001. Direito que se confunde com o próprio direito à vida, portanto sendo parte integral da ideia de cidadania plena - mesmo que não formalmente aceito o direito é implícito (LEFEBVRE, 2008) e naturalmente adquirido pelo compartilhamento do espaço e pela identidade urbanos.

No Brasil, as cidades se organizam a fim de servir ao mercado e aos métodos de produção, transformando a habitação em moeda de troca e de especulação, promovendo a segregação e a exclusão social e espacial.

A ameaça da pandemia do COVID-19 escancarou as limitações estruturais dos países no que tange à moradia, à mobilidade e aos sistemas de saúde. Em momento de comoção social, a problemática da desigualdade social se amplifica, escancarando ao mundo a fragilidades dessas organizações urbanas. Com a obrigação do isolamento social e a necessária parada das atividades produtivas e econômicas, as aglomerações urbanas precárias se tornaram alvo dos olhares temerosos, pelo seu potencial iminente de tornar-se o próximo epicentro do vírus.

Cerca de um quarto da população urbana do mundo vive em favelas. E este número está subindo rapidamente. Estimativas apontam que mais de 900 milhões de pessoas moram em favelas ao redor do mundo, se incluirmos os assentamentos informais, o número sobe a 1,6 bilhões - o que representa 1/4 da população urbana do mundo (UN - HABITAT, 2010).

Considerando que a pandemia do COVID-19 é fator exógeno que reforça as mazelas e desigualdades sociais no que tange os habitacionais precários, a intenção deste artigo é agregar um ponto a mais na discussão das favelas no Brasil. Através de um resgate histórico, foi possível identificar como se articularam as políticas públicas destinadas à moradia popular no Brasil. Para isso, foram utilizados livros, artigos e documentos que relevantes para a temática. 
No que trata especificamente do contexto da pandemia de COVID-19, em razão da contemporaneidade do cenário, o material de referência foi, em grande parcela, composto por artigos da imprensa, matérias jornalísticas e artigos científicos em formato de notícia.

\section{CNIDOSCOLUS QUERCIFOLIUS CARIOCAS}

Final do século XIX, a paisagem pré-urbanista da capital nacional, Rio de Janeiro, era caracterizada pelo desordenamento colonial entremeado pela geografia acidentada marcada por morros (PENALVA; DUARTE, 2010). Neles, surgiriam as favelas, efeito colateral não planejado de um processo de urbanização elitista, que pretendia mandar a população pobre para longe do centro da cidade, já que esses representavam uma ameaça à modernidade e ao ideal de equiparar, por meio da construção física e simbólica, a ex-colônia às capitais civilizadas europeias (SILVA, 2019).

O surgimento das favelas é anterior mesmo à instauração da República (1889), ocupações como a Quinta do Caju, a Mangueira e a Serra Morena, cujo primeiros moradores eram imigrantes portugueses, espanhóis e italianos datam de 1881 (VALADARES, 2000). Em 1897, no Morro de Santo Antônio, no centro carioca, já existiam cerca 41 barracos. Os indícios da existência desse morro foram destruídos nos anos 50 para dar lugar ao aterro do Flamengo e a Avenida Chile (NAVARRO, 2018). Igual destino teve o morro do Castelo, outro pequeno núcleo de habitações populares no centro (ZYLBERBERG, 1992).

Ainda em 1897, surge o Morro carioca mais antigo ainda existente, o da Providência. A comunidade foi inicialmente ocupada por veteranos da Guerra de Canudos (1896, sertão da Bahia) que desembarcaram na capital para reivindicar seu soldo ao governo. Ao não terem suas reinvindicações atendidas, eles passaram a construir barracos de madeira no morro que ficava atrás de um quartel (VALLADARES, 2000).

"Reza a lenda" que o Morro foi chamado de Favela em razão de uma planta nativa nos morros do sertão baiano, cenário no qual ocorreu o conflito, o arbusto "faveleira" (ZYLBERBERG, 1992). Surge um novo bairro, com cerca 623 habitantes morando em 150 casebres, que não tinham licença nem autorização das autoridades municipais (ABREU, 1994).

Será somente na segunda década do século XX que a imprensa passará a designar de favelas as aglomerações desordenadas de casebres pobres, sem acesso aos serviços públicos, 
geralmente, construídos em terrenos públicos ou de terceiros; ocupações ilegais ou irregulares, localizadas nas encostas, consideradas precárias (ABREU, 1994).

Nesse cenário, o desejo de intervir na paisagem urbana carioca, que já era reivindicação antiga de parte da elite local, ganhou força. Os surtos de febre amarela, de cólera, de varíola e de tuberculose na capital nacional preocupavam os moradores, mas em menor medida as autoridades. Especulava-se de que problemas com a falta de higiene e limpeza tinham impacto sobre a propagação dessas doenças (SOUZA, 2017), sendo que, para muitos, as habitações informais coletivas eram o resultado e a causa da desordem urbana (SILVA, 2019) que degenerava o habitat urbano.

Além de redutos de doenças, as favelas também passam a serem consideradas ambientes favoráveis a comportamentos desviantes, atribuindo aos pobres o papel de potenciais criminosos ou portadores de germes. A vinculação entre imoralidade, pobreza e saúde serviram de base para a estigmatização e marginalização das moradias populares, sendo reforma urbana, uma tentativa de disciplinar tais indivíduos (RAGO, 1985).

\section{REFORMAR PARA CIVILIZAR}

A tentativa de promover a europeização e aburguesamento da cidade trazia consigo uma mudança de comportamento e costumes. A civilização do progresso e da modernidade (europeias) materializava-se através do desenvolvimento material e o ideal burguês europeu, no embelezamento e no saneamento da cidade que rejeitavam o passado colonial (SILVA, 2019).

Assim, a partir da década de 1870, deu-se início à condenação das habitações populares, consideradas responsáveis pelas epidemias, devido a sua insalubridade. O saneamento nas capitais brasileiras começaria a ser implantado apenas na segunda metade do século XIX, dentro de um modelo restrito e com redes implantadas que acabaram não contemplando as áreas mais pobres (QUINTSLR et al., 2020).

Além de capital da República, o Rio de Janeiro era o maior centro comercial do país e deveria, portanto, ser o símbolo da civilidade nacional. Juntamente com a reforma urbanística (Reforma Urbana Pereira Passos), também foi realizada uma reforma sanitária (CONCEIÇÃO, 2017). O projeto da reforma urbana municipal (1903) associava saneamento a uma remodelação arquitetônica (SILVA, 2019). Inspirada pelas reformas urbanas ocorridas na capital francesa entre 1853 e 1870, o Rio de Janeiro passou por inúmeras intervenções 
urbanísticas que passaram pela construção de praças, abertura de vias e a ampliação de ruas. A chegada dos automóveis e a modernização dos serviços públicos com o surgimento dos sistemas de transporte coletivo: bondes puxados a burro e estradas de ferro; sistema de esgoto e de abastecimento de água; comunicação por telégrafo e telefone; iluminação a gás e energia elétrica (VAZ, 1994), influenciaram nessa reorganização do espaço urbano.

O "embelezamento" da cidade incluiu a remoção da pobreza da região central e, portanto, do afastamento de um grande contingente da população para os arredores das cidades. Era no centro que se localizavam os comércios e os empregos, sem condições de arcar com os custos de deslocamentos até o centro da cidade e não podendo abrir mão de morar na região, essa população passou a ocupar os cortiços ou as encostas de morros (PENALVA; DUARTE, 2010).

A despeito da condenação das habitações coletivas pela administração pública, principalmente na área central da cidade, as favelas acabaram sendo toleradas, crescendo com rapidez impressionante (SANTOS; MOTTA, 2003). Decretos como o de 1903 ,que proibiam a construção e o conserto dos cortiços, mas tolerava a construção de barracões nos morros; e do decreto de 1904, que ordenou a destruição de mais cortiços e habitações coletivas obrigaram os moradores a migrar em direção aos morros em busca de moradia barata e próxima ao centro da cidade (NAVARRO, 2018).

Esse efeito reverso das reformas foi na contramão do que se pretendia no "processo civilizatório" da capital da República, o que acabou suscitando um movimento em prol da extinção das favelas e dos cortiços, sob o pretexto de serem fontes de insalubridade e perigo social (VALLADARES, 2000), reivindicando a pronta solução do problema.

Em resposta às elites, em 1930, o plano do urbanista francês Alfred Agache, com remodelação do Rio de Janeiro, denunciou o perigo representado pela permanência da favela. A proibição da criação de novas favelas veio em 1937, no Código de obras. Segundo o reconhecimento de 1947, o Rio de Janeiro já somava 119 favelas, nas quais habitavam cerca de 283 mil habitantes, representando 14\% da população (NAVARRO, 2018).

\section{MORAR PARA CIVILIZAR}

O problema da habitação no Brasil é longevo e crônico, remonta desde a época do Imperador, quando da transferência da corte portuguesa para o Brasil (1808). Com a família real portuguesa, chegaram à colônia, cerca de 15 mil nobres e servos, cujo confisco das 
melhores moradias da colônia foi a medida para lhes prover residência (CAVALCANTI, 2003).

Ao ser reconhecida como um direito fundamental e social dos cidadãos, a questão da habitacional se vincula diretamente com a noção de desenvolvimento econômico e social de um país. Em contraposição, um contexto predominado por favelas e habitações precárias representam o subdesenvolvimento, a baixa escolaridade, os baixos salários, a falta de saneamento, a insalubridade, denuncia uma violação aos direitos fundamentais básicos.

As intervenções urbanas e políticas urbanísticas implementadas a partir de 1850 exilaram a população vulnerável às periferias e aos morros. Excluídos da vida social civilizada, eles precisaram encontrar alternativas financeiras viáveis para mitigar o problema da habitacional social e garantir suas atividades econômicas.

Mas a cidade continuava a crescer desordenadamente. Entre 1890-1906, a população cresceu à taxa geométrica anual de $2,84 \%$, enquanto as construções prediais expandem-se $3,4 \%$ e os domicílios, apenas $1 \%$. Comparativamente, em 1856, eram 151.700 os habitantes do Rio de Janeiro; em menos de 50 anos, em 1900, esse número subiu para 691.565 pessoas (VALLADARES, 2000).

O resultado do descompasso entre o crescimento populacional e as construções refletiu-se no aumento da densidade domiciliar, que, na época, passa de 7,3 para 9,8 pessoas por moradia (RIBEIRO, 2015). Havia gente demais e moradia de menos e a história mostrará que esse o problema só se agravou com o tempo.

Muitos foram os fatores que influenciaram nesse aumento demográfico: o fim da escravidão e a consequente substituição do trabalho escravo pelo assalariado; o aumento da imigração; a formação de mercados; a mercantilização de bens; a decadência da cafeicultura e o desenvolvimento do setor secundário e terciário da economia e a definição de novas categorias sociais no poder decorrentes da proclamação da República em 1889.

À época, a motivação para resolver o problema da moradia popular não se baseou no entendimento da importância de uma habitação adequada para o desenvolvimento econômico, mas sim de que uma habitação precária favorecia uma maior incidência de doenças e reduzia a capacidade humana para o trabalho.

Uma moradia adequada poderia ser a promotora de uma transformação cultural, tornando os indivíduos "adaptados" às exigências da moderna economia salarial (ALMEIDA, 2016) que se instalava. A nova burguesia encontrou na habitação uma mecanismos de reprodução ideológica dos valores burgueses (MILANO, 2013). Entretanto, ainda a República 
não possuía capacidade técnica, nem uma indústria de construção civil desenvolvida capaz de produzir habitação baratas que atendessem à demanda habitacional destinada à população mais pobre.

\section{TER É SER}

O desenvolvimento industrial brasileiro influenciou a indústria da construção civil. No Pós-Revolução de 1930, a industrialização nacional deslancha, agravando a crise do modelo agroexportador cafeeiro. Atraídos pelos novos postos de emprego, imigrantes e trabalhadores do campo migraram para as cidades, o que resultou em um forte crescimento dos loteamentos de antigos terrenos rurais e a construção de imóveis para locação (PENALVA; DUARTE, 2010)

Era preciso dar moradia ao novo proletariado urbano. Aos que não tinham condições de pagar aluguel, restava a opção de morar nos barracos improvisados e mal construídos, sem saneamento básico nem qualquer outro tipo de serviço. A periferização das moradias foi causa e consequência da deterioração social, física e econômica das cidades. O surgimento dos mecanismos econômicos acabou conferindo ao solo urbano funções econômicas alheias à sua utilidade intrínseca (uso) enquanto bem natural, transformando-o em objeto de demanda especulativa (BOLAFFI, 1979).

Esse crescimento desproporcional influenciou a relação entre a oferta e demanda mais pessoas do que moradias - o que acabou tornando o empreendimento urbano tão rentável economicamente quanto os investimentos nas atividades industriais (IANNI, 1977). O maior contingente de mão de obra disponível provocou uma queda no valor real dos salários, que juntamente com os efeitos da lei do inquilinato aliado a falta de investimento em habitações populares obrigou muitos a se arranjarem nas periferias como foi possível.

Durante seu primeiro mandato (1930-1945), Getúlio Vargas chegou a implementar políticas públicas com foco nas moradias precárias. Foram regulamentadas a venda de lotes à prestação (Decreto-Lei 58/1937), criadas as carteiras prediais dos Institutos de Aposentadorias e Pensões (produção direta em larga escala de conjuntos habitacionais, inicialmente financiamos pelo Estado) e publicada a Decreto-Lei do Inquilinato de 1942 que congelou os aluguéis (ALMEIDA, 2009).

Também foi criada a Fundação da Casa Popular (FCP), em 1946, o primeiro órgão nacional voltado à provisão de casas para a população de baixa renda (venda) e no 
financiamento de melhorias (PENALVA; DUARTE, 2010). Tais iniciativas deram poucos resultados, com exceção do conjunto habitacional Cruzada São Sebastião. Fundado em 1955, o conjunto habitacional está incrustado no meio do Bairro do Leblon, um dos bairros mais valorizados do Rio de Janeiro. Com influência modernista, inicialmente, o conjunto abrigou antigos moradores da favela da Praia do Pinto, mas acabou se tornando um símbolo da segregação espacial e social carioca (BARBON, 2020).

Em 1956, foi aberta uma linha de créditos especiais para auxiliar na melhoria das condições de habitação nas favelas, em uma tentativa de urbanizá-las. Porém, créditos implicam em um endividamento a médio prazo e parcelas mensais para quem sobrevive, geralmente, um salário depois do outro.

Logo que instituído, o regime militar criou o Sistema Financeiro de Habitação (SFH) em 1964 e o Banco Nacional de Habitação (BNH), órgão executor das políticas habitacionais. Com recursos provenientes da poupança compulsória (Fundo de Garantia por Tempo de Serviço - FGTS), da poupança livre (Sistema Brasileira de Poupança e Empréstimo - SBPE), e da poupança induzida (constituída de recursos próprios dos agentes financeiros ou dos adquirentes), entre 1964 e 1986, foram construídas mais de 4,5 milhões de unidades, cerca de 24\% de todo o mercado habitacional construído (BONDUKI, 2014).

A despeito dos números, boa parte das ações não foi direcionada às moradas populares, a parcela da população capaz de comprar uma casa era mínima; além disso, os planos urbanísticos elaborados no sentido de impedir o agravamento das condições de vida no país, mostraram-se ineficazes. Para piorar, a partir de 1964, o governo passa a derrubar barracos e a retirar moradores de terrenos valorizados, especialmente na Zona Sul. Até 1974, foram destruídas cerca de 80 favelas. Os 140 mil desabrigados mudaram-se para conjuntos habitacionais nas periferias ou criaram novas favelas (NAVARRO, 2018).

A problemática da habitação popular se articula diretamente com a criação de planos físicos e econômicos locais e regionais capazes de articular habitação, emprego, infraestrutura, serviços públicos e mobilidade, ignorar o aspecto global e interseccional da temática é reforçar o caos. Em um contexto no qual a habitação popular adquiriu caráter prioritário, as soluções propostas pelo Estado tinham o objetivo de mascarar as reais intenções políticas do poder em vigor, causando um distanciamento cada vez maior entre o problema real e as políticas de intervenção.

A partir de 1970, passaram a ser implementados programas com foco na urbanização das favelas, loteamentos de áreas e a autoconstrução (TASCHNER, 1997). Entretanto, o uso 
dos recursos do $\mathrm{BNH}$ apenas multiplicou a construção de habitações em série em lotes vendidos a prazo nas periferias, em um processo industrial de enfavelamento (BOLAFFI, 1979). Sem considerar a adoção de medidas eficientes voltadas ao barateamento de insumos essenciais e à produção de moradias que visassem um aumento de produtividade da indústria da construção civil; à contenção da especulação imobiliária e ao barateamento do custo dos terrenos, paulatinamente, os recursos destinados à moradia popular foram desviados para outras finalidades, dentre elas atender à demanda de habitação das classes média e alta e financiar obras de infraestrutura urbana (DENIZO, 2013).

Em prol de uma política de aquisição e expansão do mercado mobiliário, a medida de congelamento de aluguéis foi modificada passando a vigorar a Lei $\mathrm{n}^{\circ} 4.864$, de 1965, que previa a "denúncia vazia", que concedia ao locador a prerrogativa de rescindir a locação com prazo contratual vencido ou sem prazo indeterminado a qualquer momento sem nenhuma justificativa (MELLO, 2007). O estímulo ao consumo impulsionou diretamente o desenvolvimento da indústria nacional, notadamente o setor da construção civil - à época caracterizado pela forte presença do capital privado nacional. Além da geração de empregos (diretos e indiretos) aos trabalhadores pouco qualificados, o emprego geraria renda, essa poderia, em seguida, ser (re) investida no setor, por meio da aquisição da casa própria, em uma espécie de um círculo virtuoso.

Assim, surge a ideologia da casa própria, a grande aspiração da população brasileira. O oportunismo da construção desse ideal se justifica na sua vinculação com atitudes conservadoras, que se alinham com intenção permanente de se estimular comportamentos civilizados, nos "arruaceiros" moradores das comunidades. Além disso, o ciclo de aspirações da classe média, para aqueles que almejavam a ascensão social, exigia do operariado urbano sustentar um poder aquisitivo não condizente com seu contexto (BOLAFFI, 1979).

A moradia consiste em um processo de produção e logística de alta complexidade, pois além de alto valor, tornou-se um produto de consumo e pagamento (endividamento) a longo prazo e com um longo período de circulação, sendo, portanto, acessível somente como resultado de um trabalho assalariado (MARICATO, 1997).

As políticas habitacionais implementadas durante o regime militar (1964-1985) tiveram por objetivo estimular a construção de moradias populares visando o crescimento econômico, contendo o retrocesso da depressão macroeconômica e a inflação. Além disso, a adoção do ideal da casa própria garantiu o apoio popular e acabou legitimando a destinação de recursos para a construção civil que também serviu de compensação psicológica para a 
população de baixa e média baixa renda que viviam um período de contenção salarial e de apreensão pela falta de opções de moradia no mercado nas condições que pudesse assumir financeiramente (DENIZO, 2013).

Instaura-se uma das maiores contradições no que diz respeito às políticas públicas com foco habitacional: a riqueza criada na esfera pública era transferida continuamente aos proprietários sem que estes tivessem realizado qualquer investimento produtivo ou ação empresarial. As benfeitorias realizadas não se traduziam necessariamente em um aumento no imposto imobiliária na área (MILANO, 2013).

Outra distorção do sistema se refere ao duplo pagamento da propriedade, além do valor casa propriamente dito, o morador tem que dar conta da carga tributária que acompanha essa posse, o que inviabiliza em grande parte a manutenção dessa propriedade. Resultado: no final da década de 1980, calculava-se que um milhão de pessoas viviam nas 545 favelas, só no Rio de Janeiro (NAVARRO, 2018).

\section{POLÍTICAS SETORIAIS OU MACROECONÔMICAS}

As já reduzidas tentativas de promover a aquisição da casa própria não poderiam ter encontrado pior cenário, a crise econômica dos anos 80 comprometeu a viabilidade da política de sustentação da "marcha forçada" da economia brasileira em termos de investimento público (CASTRO; SOUZA, 1985), cortando a política de crédito e financiamentos. Com a renda mais que achatada, arcar com o financiamento da casa própria tornou-se impossível. A crise agilizou a extinção do $\mathrm{BNH}$, desorganizando o mercado imobiliário. Depois disso, o Brasil deixou de ter uma política habitacional, durante quase uma década, já que a busca pelo controle inflacionário se tornou uma prioridade governamental e a instabilidade política e econômica uma preocupação nacional.

O período de redemocratização foi marcado pela adoção da Constituição Federal de 1988 e caracterizou-se por um Estado com fortes investimentos na infraestrutura e na promoção do desenvolvimento industrial. Nesse contexto, a moradia retomou seu lugar de direito social cabendo ao Estado a sua garantia, configurando um dos indicadores mais completos da condição de vida de uma sociedade:

Art. $6^{\circ}$ São direitos sociais a educação, a saúde, o trabalho, a moradia, o lazer, a segurança, a previdência social, a proteção à maternidade e à infância, a assistência aos desamparados, na forma desta Constituição (BRASIL, 2016, on-line). 
A despeito do otimismo trazido pela redemocratização, a realidade dos anos que se seguiram se distanciou muito do pregado no âmbito legislativo. $O$ período de redemocratização foi marcado pela implantação de modelos institucionais e administrativos capazes de efetivar políticas públicas em respostas às demandas sociais tais como: a desburocratização; a descentralização; a parceria pública e privada e a participação da sociedade. Em contrapartida, houve desperdício de recursos e o não atendimento das questões prioritárias; a falta de legitimidade do Estado para atuar em setores estratégicos; a participação e democratização limitada e a delegação dos serviços públicos de responsabilidade do Estado para organizações não governamentais (DENIZO, 2013).

A descentralização das políticas habitacionais, que incluiu as três esferas de governo (federal, estadual e municipal), foi benéfica ao privilegiar as propostas que promoviam políticas integradas e a execução de intervenções habitacionais de forma descentralizada, especialmente com foco no aumento de sua eficiência. Porém, a inexistência de mecanismos de financiamento desenhados para atender aos mercados populares - que demandam subsídios - limitou a possibilidade de sucesso dessa descentralização. Nem todos estados e municípios tinham autonomia financeira suficiente para financiar suas próprias políticas (SANTOS, 2006). Ou seja, a homogeneidade da política habitacional era inadequada para a heterogeneidade do país, o não acomodamento das diferentes necessidades poderia acentuar as desigualdades regionais (MILANO, 2013).

Durante os mandatos de Fernando Henrique Cardoso (1995-2003), com fim do BNH, surge uma nova política habitacional que passa a utilizar o FGTS como forma de financiamento para aquisição da casa própria. Ocorreu também a municipalização das políticas habitacionais e a criação das cartas de crédito pensadas para várias faixas de renda com o intuito de beneficiar todo o mercado habitacional (CARDOSO, 2017).

O grande endividamento público obrigou a redução dos recursos na área habitacional. Com a necessidade de um "ajuste neoliberal”, vieram os cortes de gastos públicos e, com eles, a elevação de juros e a retração de crédito e, mais uma vez, as prioridades governamentais são outras. Em buscas de fundos, a criação do Sistema de Financiamento Imobiliário (SFI), em 1997, acabou por alavancar a financeirização do mercado imobiliário (PENALVA; DUARTE, 2010).

Em 1999, o lançamento do Programa de Arrendamento Residencial (PAR) retomou o subsídio direto ao financiamento habitacional. Direcionado as famílias com renda entre 3 a 6 
salários mínimos, seu foco não eram as moradias populares. O modelo organizacional e financeiro do Programa serviria de inspiração para o Programa Minha Casa Minha Vida (MCMV) que viria a ser lançado alguns anos depois, do qual o setor privado tornou agente promotor da política habitacional de interesse social (MELLO, 2007).

As políticas do período de FHC não contemplaram as moradias populares, sendo focadas em famílias de renda média alta. Prova disso é que apenas $8,47 \%$ das políticas se destinaram às famílias com renda até três salários mínimos (CARDOSO, 2017).

Com a eleição de Lula, houve uma retomada no financiamento habitacional tanto para as camadas médias quanto baixas, em razão de uma articulação entre políticas habitacional, controle e recuperação da valorização fundiária. O Ministério das Cidades (2003) e o Sistema Nacional da Habitação (SNH), em 2005, foram criados (HOLZ; MONTEIRO, 2008).

A entrada em vigor do Sistema Financeiro de Habitação Social (SFHIS) foi uma promessa de um encaminhamento adequado à superação da questão da moradia popular. Combinado com o sucesso do Sistema de Financiamento Imobiliário, criado em 1997 e com foco na produção de habitação para o mercado solvável, o SFHIS pretendia estabelecer bases mais sustentáveis para a produção de moradia dentro dos padrões legais, buscando um ordenamento mais adequado do ordenamento urbano-ambiental das cidades brasileiras (PENALVA; DUARTE, 2010).

Em 2005, já eram 1,1 milhão de pessoas vivendo em favelas apenas no Rio de Janeiro. (NAVARRO, 2018). O governo carioca implementou o Programa de Urbanização de Assentamentos Populares do Rio de Janeiro (PROAP), popularmente conhecido como FavelaBairro que realizou obras de urbanização em mais de cem comunidades pobres, como a instalação de infraestrutura urbana, serviços, equipamentos públicos e políticas sociais em comunidades da cidade do Rio de Janeiro. Vale ressaltar que o programa não é (ainda em vigor em 2020) parte de uma política habitacional, mas sim de um projeto-modelo de políticas públicas de combate à pobreza.

À época, dois projetos alteraram drasticamente o cenário nacional, o Programa de Aceleração do Crescimento 1 e 2. O PAC 1 vigorou de 2007 a 2010, com a previsão de investimento de R $\$ 657$ bilhões, o Programa previu o planejamento e a execução de grandes obras em quatro diferentes setores: infraestrutura social, urbana, logística e energética com o intuito de promover um desenvolvimento acelerado e sustentável (PAC, s.d.).

A segunda edição do Programa (PAC 2) funcionou de 2011 a 2014; com um orçamento de R $\$ 955$ bilhões, continuaram os investimentos dos quais vale citar a 
urbanização das favelas e, em saneamento ambiental, a construção de equipamentos públicos com foco na segurança e acesso a serviços essenciais como creches, unidades básicas de saúde, espaços para esporte, cultura e lazer nos bairros populares (PAC, s.d.).

Os Programas de Aceleração do Crescimento 1 e 2 contribuíram na oferta de empregos (direta e indireta) e na geração de renda por meio do investimento público e privado em obras de infraestrutura. As parcerias do Governo Federal com Estados e Municípios na execução de obras estruturantes foram fundamentais para a amplificação da quantidade e envergadura das obras (PAC, s.d.). Os impactos se sentiram na economia, dentre eles a redução dos juros, o que possibilitou o aumento do crédito imobiliário, que aliados às políticas de distribuição de renda, em última análise, alimentaram as políticas que se seguiram.

O Programa Minha Casa Minha Vida (PMCMV) foi um marco importante nas políticas com foco na produção de moradias, já que buscou ampliar o mercado habitacional para famílias até dez salários mínimos, através da distribuição de subsídios proporcionais. O Programa se baseou na parceria entre o Estado e a iniciativa privada, sendo que o último realizava a construção de moradias com financiamento do segundo.

Dentro de uma fórmula já conhecida e testada, o aquecimento do setor impactou o mercado da construção civil e, por consequência, a economia. Além de retomar a ideologia da casa própria, o Programa Minha Casa Minha Vida (PCMV) se fortaleceu devido ao seu potencial estratégico de transformar uma política direcionada à habitação em promotora do desenvolvimento econômico (MILANO, 2013).

O estímulo do Estado à produção habitacional em escala gera demandas, aumentou a produção, o consumo, as oportunidades de empregos em vários setores e o aumento da renda média da população, em geral - colateralmente promovendo um impacto social. Isso corrobora a hipótese de que o aumento da oferta de moradias promovidas pelo poder público contribuiria para diminuir as despesas com habitação da população alvo, promovendo um aumento relativo de seu poder aquisitivo (consumo e investimento) e, portanto, da sua condição de vida (DENIZO, 2013).

Mas essa equação não fecha, pois há outros fatores a serem considerados. Dentre elas a prestação do financiamento da casa que, apesar de serem menores que o preço do aluguel, devido aos subsídios, representa um endividamento a longo prazo. A propriedade de uma casa também implica no pagamento de serviços que antes eram obtidos de forma irregular ou gratuita em razão de ligações clandestinas de energia elétrica, furto de água. Além disso, há o 
pagamento de impostos e outras despesas complementares como transporte entre outros (MILANO, 2013). Ou seja, a propriedade de uma casa traz consigo uma gama de novas despesas que parecem ter sido negligenciadas no escopo do projeto.

Durante o mandato da presidente Dilma (2011-2016), há uma tentativa de se implementar uma segunda versão do PMCMV 2, mas esse não alcança os mesmos resultados da versão inicial. A crise econômica e o esgotamento de recursos que reduziu os postos de trabalho aliados aos escândalos de corrupção que resultaram na Operação Lava-Jato levaram a uma crise institucional que terminou com o impeachment da presidente, em 2016 (CARDOSO, 2017).

Com o governo provisório de Temer, o PMCMV mudou de público foco, reduzindo progressivamente o orçamento destinado ao programa de 20 bilhões em 2015 para 4,6 em 2018 (TOMAZELLI, 2019). O cartão reforma foi criado para fornecer subsídio de cerca de R \$ 5 mil para a compra de materiais de construção. O Programa previu atender cerca 182 mil famílias, mais contemplou apenas 150 (AMARAL, 2017; SOUZA; HOFF, 2019).

Por meio da Medida Provisória ${ }^{\circ} 870$, de $1^{\circ}$ de janeiro de 2019, no governo de Jair Bolsonaro, empossado em 2019, os Ministério da Integração Nacional (MI) e das Cidades (MCid) foram unificados e substituídos pelo Ministério do Desenvolvimento Regional (MDR). Sendo as pastas de habitação, segurança hídrica e saneamento passadas à responsabilidade do novo Ministério delegadas à Secretaria Nacional de Habitação (SNH), Secretaria Nacional de Saneamento (SNS) e da Secretaria Nacional de Segurança Hídrica (SNSH), respectivamente.

Segundo dados no MDR, em 2019, o Programa de Habitação de Interesse Social recebeu $\mathrm{R} \$ 4,2$ bilhões ou 4,6 bilhões (as informações divergem), do quais $85 \%$ foi destinado ao atendimento de famílias com renda mensal de até $\mathrm{R} \$ 1.800$ - totalizando 350,6 mil residências entregues em todas as faixas do programa PMCMV. Até abril de 2020, foram 667,7 milhões investidos em programas de casa própria, sendo a maior parte dos recursos destinada à continuidade das obras de 301 mil moradias para famílias que ganham até R\$ 1.800 reais (GOVERNO DO BRASIL, 2020a).

No início de 2020, foram anunciadas alterações no PMCMV: para subsídios de até $90 \%$ do valor total do imóvel, o teto estabelecido de acesso passaria de $\mathrm{R} \$ 1.800$ para $\mathrm{R} \$$ 1.200 - reduzindo o orçamento do programa de cerca de $\mathrm{R} \$ 4,6$ bilhões (BRASIL, 2019) para $\mathrm{R} \$ 2,7$ bilhões (RBA, 2019). 
A mudança atingiria às faixas de menor renda, diminuindo a oferta de moradia populares, bem como todo o processo inerente à longa cadeia produtiva da construção civil. Entretanto, com o desencadeamento da pandemia de COVID-19 e os impactos econômicos consequentes do isolamento social e da sobrecarga sobre os gastos públicos, é possível que tais medidas sejam revistas (para pior ou melhor). Já que dentro do plano de recuperação economia, pós-pandemia, o Pró-Brasil, os principais pontos da proposta são gerar emprego e recuperar a infraestrutura do país, ou seja, priorizar uma expansão de investimentos na construção civil (MENEZES, 2020; LARGHI, 2020).

Em 2019, o saneamento básico (abastecimento de água potável, o esgotamento sanitário, a limpeza urbana, o manejo de resíduos sólidos, a drenagem e o manejo das águas pluviais e a limpeza e a fiscalização preventiva das respectivas redes urbanas) foi incluso pelo Decreto 10.143, de 28/11/2019, que atualizou o Fundo Nacional sobre Mudança do Clima, ou Fundo Clima criado pela Lei 12.114 em 09/12/2009 (BNDES, s.d.; G1, 2019).

Um dos instrumentos da Política Nacional sobre Mudança do Clima, o Fundo Clima, tem por finalidade de garantir recursos para apoio a projetos e empreendimentos que tenham como objetivo a mitigação das mudanças climáticas. Essa inclusão representou uma conquista importante, já que passa a considerar o saneamento básico como componente no processo de mitigação das mudanças do clima.

Além disso, o Ministério do Desenvolvimento Regional destinou mais de R\$ 593 milhões a projetos de saneamento básico e outro $\mathrm{R} \$ 1,14$ bilhão em financiamentos ativos para o setor com o intuito de retomar 128 obras que estavam paralisadas e finalizar 106 empreendimentos que vão beneficiar mais de um milhão de famílias.

Analisando o resgate histórico, o que predomina são iniciativas de articulação e gestão integrada de políticas públicas na estruturação do espaço urbano que acentuam o aprofundamento da abordagem setorial, sem foco real no desenvolvimento social e urbano. As intervenções do Estado na questão habitacional tendem a se tornar insustentáveis no horizonte espaço-tempo, uma vez que seus beneficiários, apesar do acesso a uma moradia, continuam excluídos da educação, do trabalho e das oportunidades que a urbanização possibilita para o desenvolvimento coletivo. Assim, quanto mais se urbaniza as favelas, maior o déficit e as inadequações habitacionais (DENIZO, 2013). 


\section{SARS-COV2 E A MORADIA POPULAR}

Os primeiros casos da COVID-19, doença causada pelo vírus SARS-CoV2, no mundo, foram identificados em Wuhan, na China, no dia 31 de dezembro do 2019 (WHO, 2020). No Brasil, pesquisadores sugerem que o primeiro caso tenha ocorrido em janeiro de 2020 (BBC, 2020), diferente da narrativa oficial que estabeleceu o primeiro caso como sendo de um homem de 61 anos, morador da cidade de São Paulo que havia retornado de uma viagem à Itália (G1, 2020).

Após atingir mais de 114 países, em 11 de março de 2020, a Organização Mundial da Saúde (OMS) declara estado de pandemia (WHO, 2020). Doze meses passados do primeiro caso identificado, o mundo já ultrapassou a marca de 104 milhões de casos, com mais de 2,2 milhões de óbitos (JOHNS HOPKINS, 2021).

À medida que combatem o vírus, os pesquisadores passam a conhecer melhor seus efeitos e impactos. Já se sabe da ausência de sintomas, a uma gripe simples, o vírus pode causar síndrome respiratória agudas e outros sintomas (CAVALCANTE et al, 2021). Dentre as intervenções, não farmacológicas, defendidas pela Organização mundial da Saúde estão: a lavagem de mãos com água e sabão ou com desinfetantes para mãos à base de álcool; o cobrimento de boca e nariz com lenço descartável ao tossir ou espirrar e o distanciamento social (WHO, 2021).

Diferente de países como o Estados Unidos, no qual não há um sistema de saúde pública estruturado e gratuito, o Sistema Único de Saúde (SUS) ganhou relevância e reforçou sua importância no contexto brasileiro de pandemia, em meio a rumores de privatização. Sendo que o único ponto de concordância entre as autoridades foi a necessidade de estruturação e reforço do Sistema Único de Saúde (SUS) para ampliar a capacidade de absorção da demanda para adiar o seu colapso - com um foco maior no tratamento dos infectados, afastando-se de uma estratégia de enfrentamento com foco na prevenção.

Construção de hospitais de campanha; a compra de EPI's (equipamento de proteção individual) para os profissionais da saúde; a aquisição e forças tarefa para conserto de ventiladores pulmonares; o lançamento de editais emergenciais de contratação; a dispensa de licitações para a compra de materiais com a finalidade de combater o vírus; a facilitação no reconhecimento de diplomas de médicos formados no exterior; o adiantamento na formatura de profissionais da área da saúde; a convocação de profissionais das demais áreas da saúde são parte das medidas adotadas (GOVERNO DO BRASIL, 2020b). 
A falta de homogeneização no enfretamento da pandemia, os discursos desencontrados das autoridades, a falta de testagem, incongruências nas estatísticas de casos e óbitos acabou por transformar a crise sanitária em política. As autoridades municipais, estaduais e federais enfrentam dificuldades em alinhar o discurso a respeito das medidas de isolamento, e mais recentemente, sobre os protocolos de vacinação, o que prejudica na rápida adoção de medidas e como consequência, o achatamento da curva de contaminação. Como resultado, o Brasil já está perto dos 10 milhões de casos, com 220 mil óbitos, atrás apenas dos Estados Unidos e a Índia (JOHNS HOPKINS, 2021).

\section{PANDEMIA E DESIGUALDADE}

As incertezas (científicas, econômicas, sociais, políticas) trazidas pela crise sanitária escancaram as mazelas locais e colocam sistemas à prova, acelerando o colapso de estruturas falhas ou insuficientes. Se os países desenvolvidos entraram em colapso quando chegaram ao pico de contágio da COVID-19, quais serão os desdobramentos nos países mais pobres caracterizados por alta densidade demográfica, sistemas de saúde precários e contexto sócio ambiental insalubre.

As consequências do COVID-19 resultantes das interações com a desnutrição e as infecções existentes ainda são desconhecidas, o que serve de advertência de que a COVID-19 pode tomar um caminho diferente e mais mortal nos bairros mais populares. Ninguém sabe (e não saberá por muito tempo) como o vírus pode interagir com as condições de saúde e as doenças locais (DAVIS, 2020).

Existe uma falsa ideia de que o vírus seria democrático, em razão do seu potencial e meio de contágio que não discriminam classe social, raça ou credo. Na prática, a história não se desenrolou assim. Inicialmente, o vírus circulou na faixa da população que tem acesso às viagens internacionais, aproveitando a livre circulação de pessoas por meio do tráfego aéreo. Mas, a partir do momento que já existe o contágio local (transmissão comunitária), tal ideia cai por terra.

Ao ser perguntada sobre as especificidades da COVID-19 no Brasil, a Presidente da Fiocruz, Nísia Trindade Lima, ressaltou os impactos da dimensão socioespacial:

A Covid-19 está se intensificando no Brasil primeiro em dois grandes centros, o que é natural, uma vez que veio pelo tráfego aéreo. Chega de classe executiva, mas se depara com uma realidade em que nós temos uma alta densidade populacional e em 
condições habitacionais de muitas vulnerabilidades, como é o caso de muitas das nossas periferias e favelas em todos os centros urbanos do Brasil. Além disso, temos uma mobilidade urbana difícil, transportes lotados, uma série de questões que vão interferir no curso da epidemia. (...) (DIAS, 2020, on-line).

O imperativo do isolamento parece não ter incluído os indivíduos que mal têm um "lar" ou nenhum, para que possam, mesmo assim, encontrar um abrigo seguro (BADIOU, 2020). Não há democracia na desigualdade. A viabilidade de adotar as orientações da OMS, tanto no que diz respeito ao reforço dos hábitos de higiene pessoal quanto em manter o isolamento social por meio do home office ou evitar o transporte coletivo é privilégio de poucos.

Com quase metade da mão de obra ativa brasileira trabalhando na informalidade, são cerca de 38 milhões de brasileiros que não têm a escolha senão ir ao trabalho para poder sobreviver (ATAIDE et al, 2020), trabalhar em casa é algo inalcançável para essas famílias (GORTÁZAR, 2020). A situação se agrava com o fechamento das escolas e a suspensão das aulas, o que configura, em muitos casos, a cessão da única fonte de alimentação de qualidade de muitos alunos e a presença constante das crianças nas residências.

As populações vulneráveis, além de viverem em condições favoráveis ao desenvolvimento de infecções e epidemias (ALMEIDA, 2016), sofrem as maiores consequências ao contrair o vírus, em função de doenças e problemas de saúde pré-existentes (ATAIDE et al, 2020), ou mal tratados - pela dificuldade de acesso aos sistemas de saúde ou pela incapacidade de se submeterem a um tratamento de saúde contínuo.

A recorrente falta de água impossibilita à devida higienização das mãos. Nesse contexto, seguir qualquer recomendação sanitária mais simples é impossível, ainda a alta demanda por produtos de higiene pessoal como sabão e álcool gel, resultou em uma alta precificação desses produtos, tornando-os ainda mais inacessíveis para o poder aquisitivo de boa parte da população (GORTÁZAR, 2020).

As políticas de abastecimento de água e esgotamento sanitário nos países subdesenvolvidos não foram objeto de uma efetiva política pública de universalização do acesso. Os avanços da medicina moderna que facilitaram o acesso ao tratamento para diversas doenças de veiculação hídrica às classes médias urbanas, acabou minando as motivações de financiamento para expansão das redes em áreas habitadas por grupos mais vulneráveis (BARRAQUÉ; ZANDARYAA, 2011).

Cerca 30 milhões de brasileiros que não têm saneamento básico e 35 milhões permanecem sem acesso à água potável em quantidade e qualidade desejáveis - abastecimento Pensar Acadêmico, Manhuaçu, v. 19, n. 2, p. 407-432, maio-setembro, 2021 
de água atende a 83,6\% dos brasileiros (RODRIGUES; BERTOLOTTO, 2020). O sistema de esgoto não contempla 100 milhões de pessoas, sendo que apenas 46,3\% do esgoto gerado no país são tratados e o (LIS, 2019).

O panorama de calamidade anuncia uma crise urbana que emergirá como resultado do histórico de negligência dado às questões das moradias populares e benfeitorias. A velocidade do vírus será acelerada em um contexto no qual famílias inteiras vivem em cômodos apertados e mal ventilados, inclusive idosos. São regiões de alta densidade populacional, caracterizadas por moradias amontadas, umas sobre à outras, sem infraestrutura nem saneamento básico. A coabitação é uma consequência do déficit habitacional e das limitações sócio financeiras de grande parte dos brasileiros, tornando impossível se proteger do contágio ou isolar-se para evitar a propagação.

Estudos apontaram que, na China, primeiro epicentro da pandemia, o número de mortes foi duas vezes maior em setores mais pobres do país (FISHER; BUBOLA, 2020) - o que atesta a pobreza como um importante fator de risco. Em exemplo local, é Brasilândia, bairro localizado na Zona Norte de São Paulo. O bairro concentra um dos maiores índices de mortes confirmadas ou suspeitas do COVID-19 no Brasil, com um média de 113 mortes a cada cem mil habitantes (HIAR; BIAZZI, 2020). Com um contexto já marcado por múltiplas carências, a Brasilândia tem quase 265 mil moradores, totalizando 13 mil habitantes por quilômetro quadrado. Enquanto no Morumbi, bairro nobre da capital Paulista, a densidade é de cerca de 4 mil moradores por quilômetro quadrado (AÇÃO COVID 19, s.d.) Mesma situação enfrenta o distrito de Sapopemba, na zona leste, com uma densidade demográfica bruta ainda maior, 21.076 hab/km² (Ação COVID 19, 2020).

As sociedades atingidas pelo vírus SARS-CoV-2 têm testemunhado um aprofundamento das consequências da desigualdade, impactando fortemente os mercados e as economias. Pesquisas sugerem que aqueles que se encontram nos estratos econômicos mais baixos são mais suscetíveis para serem infectados e chegarem a óbito. De acordo com um estudo de 2010 de uma revista britânica de ciências biológicas, Proceedings of the Royal Society $B$, comunidades inteiras podem ficar presas em uma espécie de armadilha da pobreza causada por doenças. Esse ciclo de reforço mútuo influencia na alavancagem do vírus a medida que amplia a desigualdade socioeconômicas, consideradas como os impulsionadores da animosidade racial e mortes por desespero - resultantes de alcoolismo, suicídio ou overdose de droga (FISHER; BUBOLA, 2020). 


\section{CONSIDERAÇÕES FINAIS}

Estigmatizada como reduto da pobreza e da criminalidade e negligenciada no contexto das políticas habitacionais brasileiras, as favelas têm sido relegadas ao oblívio em uma tentativa deliberada de que o esquecimento resulte em desaparecimento. Os danos da desigualdade são brutais, tratar de pandemia nas favelas e falar de sobrevivência é quase redundante.

As políticas públicas recentes com foco na moradia popular dos últimos dez anos, não se mostraram suficientes para recuperar uma lacuna construída durante mais de 50 anos, agravando uma situação que já era preocupante. Mesmo que garantida constitucionalmente, o Estado tem se mostrado incapaz de universalizar o acesso à moradia e dar uma resposta sustentável para a questão da moradia social popular.

A emergencialidade do combate à pandemia, infelizmente não é capaz de resolver problemas estruturais crônicos que são resultado de um histórico de negligência do Estado. O medo paira sobre as comunidades, para combater o inimigo invisível são precisos recursos, produtos e, inclusive, informação que não se tem.

A questão habitacional extrapola os limites das políticas setoriais de habitação em curso, que ainda consideram como indicador de eficiência o quantitativo de habitações construídas ou favelas urbanizadas. Novos paradigmas devem ser agregados à reflexão que tenham como meta reverter os processos de exclusão sócio espacial e instaurem um novo institucional que rompam com a visão setorial da questão, articulando moradia, desenvolvimento e meio ambiente, levando em consideração as diferentes realidades do país.

Espaço de afirmação e de identidade própria, por meio de coletivo e participação popular, as favelas têm rompido o silenciamento e vêm demonstrando que as comunidades representam não apenas uma local de moradia, mas carregam em si um potencial de transformação da realidade de seus moradores - tornando-se um espaço de resistência e denúncia.

Denúncia das injustiças, das precariedades e da desigualdade que grita aos ouvidos moucos da sociedade e das autoridades. Em contexto de pandemia, no qual a saúde pública parece ter se tornado uma responsabilidade individual, inúmeras iniciativas entre a sociedade civil, o terceiro setor e setor privado têm sido implementadas como medidas paliativas para tentar mitigar o contágio dentro das comunidades. Mas nenhuma delas será tão permanente e transformadora do que a atuação planejada e ordenada do Estado. 


\section{REFERÊNCIAS}

ABREU, M. de. Reconstruindo uma história esquecida: origem e expansão das favelas do Rio de Janeiro. Espaço \& Debates, 37: 34-46, 1994.

AÇÃO COVID 19. São Paulo: Uma cidade, muitas curvas: entre Brasilândia, Sapopemba e Jardins. São Paulo, julho de 2020. Disponível em: https://acaocovid19.org/saopaulo. Acesso em: 25 mar.2020.

ALMEIDA, C. C. O. As quatro décadas de atuação dos Institutos de Aposentadoria e Pensões (IAPs) em Natal-RN: a arquitetura habitacional resultante. In: DOCOMOMO Brasil, 8, 2009, Rio de Janeiro. Anais do 8 DOCOMOMO Brasil. Rio de Janeiro, 2009. (CD-Trabalhos Completos).

ALMEIDA, R. G. Favelas do Rio do Janeiro: A geografia histórica da invenção de um espaço. 2016. p, 523. Tese (Doutorado - Programa de Pós-Graduação em Geografia) Universidade Federal do Rio de Janeiro, Rio de Janeiro, 2016.

AMARAL, L. Um ano após lançamento, somente 150 famílias receberam Cartão Reforma. UOL Economia. Brasília, 13 novembro 2017. Disponível em: https://economia.uol.com.br/noticias/redacao/2017/11/13/cartao-reforma-entrega-r-9646.htm. Acesso em: 25 mar.2020.

ATAIDE, R.; GUIMARÃES, E.; BRASIL, A.; MORETTI, R. Quem tem fome tem pressa: as respostas lentas do Estado frente à ameaça do coronavírus nas periferias do Brasil. Observatório das Metrópoles - Corona Vírus e as Periferias do Brasil. 09 de abril 2020. Disponível em: https://www.observatoriodasmetropoles.net.br/quem-tem-fome-tem-pressaas-respostas-lentas-do-estado-frente-a-ameaca-do-coronavirus-nas-periferias-do-brasil/.

Acesso em: 25 abr.2020.

BARBON, J. Destoantes, dez prédios populares resistem no coração do Leblon. Folha de São Paulo. Rio de Janeiro. 28 de julho de 2020. Disponível em: https://www1.folha.uol.com.br/cotidiano/2018/07/destoantes-dez-predios-populares-resistemno-coracao-do-leblon.shtml. Acesso em: 04 jan.2021.

BBC. Coronavirus: First Brazil death 'earlier than thought. Latin America. BBC News, 12 de maio de 2020. Disponível em: https://www.bbc.com/news/world-latin-america-52638352. Acesso em: 04 jan.2021.

BARRAQUÉ, B.; ZANDARYAA, S. Urban Water Conflicts: Background and conceptual framework. In: BARRAQUÉ, B. (Org.). Urban Water Conflicts. UNESCO-IHP. ed.: CRC Press, 2011. p. 1-14.

BNDES. (s.d.). Fundo Clima. Disponível: https://www.bndes.gov.br/wps/portal/site/home/financiamento/produto/fundo-clima. Acesso em: 25 abr. 2020 . 
BOLAFFI, G. Habitação e urbanismo: o problema e o falso problema. MARICATO, E. (Org). A produção capitalista da casa (e da cidade) no Brasil industrial. São Paulo: Alfa-Ômega, 1979.

BONDUKI, N. G. Pioneiros da Habitação Social: cem anos de construção de política pública no Brasil. São Paulo: Editora Unesp e Edições SESC, 2014, v. 1, 387 p.

BRASIL. Constituição da República Federativa do Brasil de 1988. Brasília, DF: Presidência da República, (2016). Disponível em: http://www.planalto.gov.br/ccivil_03/constituicao/constituicao.htm. Acesso em: 01 abr.2020.

CARDOSO, A, L; ARAGÃO, T A; JAEnisch, S T. Vinte e Dois Anos de Política Habitacional no Brasil: da euforia à crise. Rio de Janeiro, Letra Capital, Observatório das Metrópoles, 2017.

CASTRO, A. B. DE; SOUZA, F. E. P. de. A economia brasileira em marcha forçada. Rio de Janeiro, Paz e Terra, 1985.

CAVALCANTE, João Roberto et al . COVID-19 no Brasil: evolução da epidemia até a semana epidemiológica 20 de 2020. Epidemiol. Serv. Saúde. Brasília, 29 (4), 2020. Disponível em: http://www.scielo.br/scielo.php?script=sci_arttext\&pid=S223796222020000400306\&lng=en\&nrm=is. Acesso em: 02 fev.2020.

CAVALCANTI, N. O Rio de Janeiro setecentista: a vida e a construção da cidade da invasão francesa até a chegada da Corte. Rio de Janeiro: Jorge Zahar Editor Ltda, 2003.

CONCEIÇÃO, D. da. A Reforma Pereira Passos e seus impactos sobre a cidade do Rio de Janeiro. ENCONTROS, 15(29), 38-48, 2017.

DAVIS, M.; HARVEY, D.; ZIBECHI, R.; Žižek, S. Coronavírus e a luta de classes. Terra sem Amos: Brasil, 2020.

DENIZO, V. Papéis do Estado na questão habitacional: reflexões conceituais. In: Anais do XV Encontro da Associação Nacional de Programas de Pós-Graduação e Pesquisa em Planejamento Urbano e Regional. Recife: ANPUR, MDU, UFPE, 2013.

DIAS, J. Covid-19: presidente da Fiocruz fala dos desafios da da chegada da pandemia ao Brasil. Portal FIOCRUZ. Rio de Janeiro, 26 de março de 2002. Disponível em: https://portal.fiocruz.br/noticia/covid-19-presidente-da-fiocruz-fala-dos-desafios-da-chegadada-pandemia-ao-brasil. Acesso em: 10 abr.2020.

FISHER, M., \& BUBOLA, E. (2020). As Coronavirus Deepens Inequatlity, Inequality Worsens Its Spread. The New York Times - The Interpreter. 15 de março de 2020. Disponível em: https://www.nytimes.com/2020/03/15/world/europe/coronavirusinequality.html. Acesso em: 10 abr.2020.

G1. Decreto de Bolsonaro inclui saneamento básico e mobilidade urbana entre prioridades do Fundo Clima. Portal G1 - Natureza. 29 de novembro de 2019. Disponível: https://g1.globo.com/natureza/noticia/2019/11/29/decreto-de-bolsonaro-inclui-saneamento- 
basico-e-mobilidade-urbana-entre-prioridades-do-fundo-clima.ghtml. Acesso em: 10 mar. 2020.

G1. Primeiro caso confirmado de Covid-19 no Brasil ocorreu em SP e completa seis meses nesta quarta. Portal G1 - São Paulo. São Paulo, 26 de agosto de 2020. Disponível em: https://g1.globo.com/sp/sao-paulo/noticia/2020/08/26/primeiro-caso-confirmado-de-covid-19no-brasil-ocorreu-em-sp-e-completa-seis-meses-nesta-quarta.ghtml. Acesso em: 10 set.2020.

GORTÁZAR, N. G. Coronavírus chega às favelas brasileiras com impacto mais incerto que nas grandes cidades. El País, Pandemia de Coronavírus. 05 de abril 2020. Disponível em: https://brasil.elpais.com/sociedade/2020-04-05/coronavirus-chega-as-favelas-brasileiras-comimpacto-mais-incerto-que-nas-grandes-cidades.html. Acesso em: 25 abr.2020.

GOVERNO DO BRASIL. Governo Federal retoma obras de programa de habitação popular. Notícias - Cidadania e Assistência Social - Habitação. Brasília, 26 de maio de 2020a. Disponível em: https://www.gov.br/pt-br/noticias/assistencia-social/2020/05/governo-federalretoma-obras-de-programa-de-habitacao-popular. Acesso em: 10 set.2020.

GOVERNO DO BRASIL. Saúde destaca reforços no SUS para o combate à pandemia. Assuntos - Agência Saúde. Brasília, 10 de dezembro de 2020b. Disponível em: https://www.gov.br/saude/pt-br/assuntos/noticias/saude-destaca-reforcos-no-sus-para-ocombate-a-pandemia. Acesso em: 10 jan.2021.

HIAR, R.; BIAZZI, R. Sapopemba lidera ranking de bairros com mais mortes por Covid-19 em SP pelo terceiro mês seguido. Portal G1 - São Paulo. São Paulo, 03 de setembro de 2020. Disponível em: https://g1.globo.com/sp/sao-paulo/noticia/2020/09/03/sapopembalidera-ranking-de-bairros-com-mais-mortes-por-covid-19-em-sp-pelo-terceiro-messeguido.ghtml. Acesso em: 10 set.2020.

HOLZ, S.; MONTEIRO, T. V. de A. Política de habitacão social e o direito a moradia no Brasil. Diez años de cambios en el Mundo, en la Geografía y en las Ciencias Sociales, 19992008. Actas del X Coloquio Internacional de Geocrítica. Universidad de Barcelona, 26-30 de maio de 2008. Disponível em http://www.ub.es/geocrit/-xcol/158.htm. Acesso em: 10 mar. 2020 .

IANNI, O. Estado e planejamento econômico no Brasil. Rio de Janeiro: Civilização Brasileira, 1977.

JOHNS HOPKINS. COVID-19 Dashboard by the Center for Systems Science and Engineering (CSSE) at Johns Hopkins University (JHU). 04 de fevereiro de 2021. Disponível em: https://coronavirus.jhu.edu/map.html. Acesso em: 04 fev.2021.

LARGHI, N. Saiba o que é o Plano Pró-Brasil e o que economistas acham dele. Valor Investe - Brasil e Política. 24 de abril 2020. Disponível: https://valorinveste.globo.com/mercados/brasil-e-politica/noticia/2020/04/24/saiba-o-que-e-oplano-pro-brasil-e-o-que-economistas-acham-dele.ghtml. Acesso em: 25 abr.2020.

LEFEBVRE, H. O direito à cidade. 5.ed. São Paulo: Centauro, 2008. 
LIS, L. Metade da população brasileira não tem acesso a rede de esgoto, diz ministério. Portal G1 - Economia. Brasília, 10 de dezembro de 2019. Disponível em: https://g1.globo.com/economia/noticia/2019/12/10/metade-da-populacao-brasileira-nao-temacesso-a-rede-de-esgoto-diz-ministerio.ghtml. Acesso em: 25 jan.2021.

MARICATO, E. Brasil 2000: qual planejamento urbano? Cadernos IPPUR, Rio de Janeiro, Ano XI, n. 1 e 2, p. 113-130, 1997.

MELLO, F. P. L. A transformação da propriedade imobiliária na cidade de São Paulo no período de 1980 a 2005: o caso dos produtos de locação de uso residencial. 2007. p, 308. Dissertação. (Mestrado, Programa de Pós-Graduação em Arquitetura e Urbanismo) Universidade São Judas Tadeus, São Paulo, 2007.

MENEZES, P. Plano "Pró-Brasil" põe um fim à era do "Posto Ipiranga". Infomoney - Pedro Menezes. São Paulo, 25 de abril de 2020. Disponível: https://www.infomoney.com.br/colunistas/pedro-menezes/plano-pro-brasil-poe-um-fim-naera-do-posto-ipiranga/. Acesso em: 25 abr.2020.

MILANO, J. Z. Aluguel Social no Brasil: algumas reflexões sobre a ideologia da casa própria. In: XV Encontro da Associação Nacional de Pós-Graduação e Pesquisa em Planejamento Urbano e Regional. Recife, 2013.

NAVARRO, R. Qual foi a primeira favela do Brasil? Super Interessante - Mundo Estranho. São Paulo, 18 de abril de 2011. Disponível em https://super.abril.com.br/mundoestranho/qual-foi-a-primeira-favela-do-brasil/. Acesso em: 20 abr.2020.

OECD. Informal Settlements. Glossary of statistical terms. Organisation for Economic Cooperation and Development - Glossary. 25 de setembro de 2001. Disponível em: https://stats.oecd.org/glossary/detail.asp?ID=1351. Acesso em: 13 mar.2020.

PAC. Sobre o PAC. Ministério do Planejamento - PAC. s.d. Disponível em: http://pac.gov.br/sobre-o-pac. Acesso em: 20 abr.2020.

PENALVA, A. M. S.; DUARTE, S. M. Política Habitacional No Brasil: uma nova abordagem para um velho problema. RFD - Revista da Faculdade de Direito da UERJ, 1 (18), abr. 2010. Disponível em: https://www.e-publicacoes.uerj.br/index.php/rfduerj/article/view/1375. Acesso em: 12 abr.2020.

QUINTSLR, S.; BRITTO, A. L.; DIAS, M. Coronavírus: reflexões acerca da pandemia global e sua relação com o direito à água e ao esgotamento sanitário. Observatório das Metrópoles - Corona Vírus e o Direito à água e ao Esgotamento Sanitário. 02 de abril 2020. Disponível em: https://www.observatoriodasmetropoles.net.br/coronavirus-reflexoes-acercada-pandemia-global-e-sua-relacao-com-o-direito-a-agua-e-ao-esgotamento-sanitario/. Acesso em: 25 abr. 2020 .

RAGO, L. M. Do cabaré ao lar: a utopia da cidade disciplinar. 3. ed. Rio de Janeiro: Paz e Terra, 1985. 
RBA. Com novas medidas de Bolsonaro, 2020 será o pior ano do Minha Casa Minha Vida. Rede Brasil Atual - Cidadania. 17 de setembro de 2019. Disponível em: https://www.redebrasilatual.com.br/cidadania/2019/09/medidas-de-bolsonaro-minha-casaminha-vida/. Acesso em: 25 abr.2020.

RIBEIRO, L. C. de Q. Dos cortiços aos condomínios fechados: as formas de produção da moradia na cidade do Rio de Janeiro. [recurso eletrônico]. Rio de Janeiro: Letra Capital, 2015.

RODRIGUES, P.; BERTOLOTTO, R. Água e Sabão: métodos de prevenção contra o coronavírus são luxo para milhões de pessoas afetadas pela desigualdade social no brasil. Portal UOL - ECOA. São Paulo, 14 de março de 2020. Disponível em: https://www.uol.com.br/ecoa/reportagens-especiais/coronavirus-desigualdade-do-brasil-podepiorar-a-situacao-da-pandemia/index.htm\#agua-e-sabao. Acesso em: 25 abr.2020.

SANTOS, A. M. S. P. Federalismo no Brasil: da autonomia à cooperação. In: PAULA, L. F. R.; FERREIRA, L. R.; ASSIS, M. (org.). Perspectivas para a economia brasileira. Inserção internacional e políticas públicas. Rio de Janeiro: EdUERJ, 2006.

SANTOS, A. M. S. P.; MOTTA, M. S. O "bota-abaixo" revisitado: o Executivo municipal e as reformas urbanas no Rio de Janeiro (1903-2003). [recurso eletrônico]. Revista Rio de Janeiro, 10, maio-agosto, 2003. Acesso em: 25 abr.2020.

SILVA, M. G. C. F. Algumas considerações sobre a reforma urbana Pereira Passos. urbe. Revista Brasileira de Gestão Urbana, 11, 2019. Disponível em: https://doi.org/10.1590/2175-3369.011.e20180179. Acesso em: 25 abr.2020.

SOUZA, D. S. de. Favela, o "sertão" da cidade": o arraial de Canudos no imaginário acerca das primeiras favelas cariocas. 2017. p, 104. Dissertação (Graduação em História) Pontifícia Universidade Católica do Rio de Janeiro, Rio de Janeiro, 2017.

SOUZA, M. B., \& HOFF, T. S. R. Governo Temer e a volta do neoliberalismo no Brasil: possíveis consequências para a habitação popular. Urbe - Revista Brasileira de Gestão Urbana, [S.1.], 11, maio 2019. Disponível em: https://periodicos.pucpr.br/index.php/Urbe/article/view/24652. Acesso em: 25 abr.2020.

TASCHNER, S. P. Política habitacional no Brasil: retrospectivas e perspectivas. Cadernos de Pesquisa do LAP 21 - Série Habitação Popular. São Paulo: FAU, 1997.

TOMAZELLI, I. O material jornalístico produzido pelo Estadão é protegido por lei. As regras têm como objetivo proteger o investimento feito pelo Estadão na qualidade constante de seu jornalismo. Estadão - Economia \& Negócios. São Paulo, 02 de setembro de 2019. Disponível em: https://economia.estadao.com.br/noticias/geral,na-berlinda-por-falta-de-verbaminha-casa-minha-vida-vive-maior-aperto-desde-sua-criacao,70002993151. Acesso em: 25 abr.2020.

UN - HABITAT. State of the World's cities 2010/2011: Bridging the Urban Divide. United Nations Human Settlements Programme, 2010. Disponível em: 
https://sustainabledevelopment.un.org/content/documents/11143016_alt.pdf. Acesso em: 25 abr.2020.

VALLADARES, L. A gênese da favela carioca. A produção anterior às ciências sociais. Revista Brasileira de Ciências Sociais, 15(44), 05-34, 2000. Disponível em: https://doi.org/10.1590/S0102-69092000000300001. Acesso em: 25 abr.2020.

VAZ, L. F. Dos cortiços às favelas e aos edifícios de apartamentos - a modernização da moradia no Rio de Janeiro. Revista do Instituto de Ciências Sociais da Universidade de Lisboa, 24, 127: 581-97, 1994.

WHO. Coronavirus disease (COVID-19) advice for the public. World Health Organization - Emergences - Diseases - Coronavirus disease (COVID-19). 22 de janeiro de 2021. Disponível em: https://www.who.int/emergencies/diseases/novel-coronavirus-2019/advicefor-public. Acesso em: 25 jan.2021.

WHO. WHO Timeline - COVID-19. News. World Health Organization - News Archived: WHO Timeline - COVID-19. 27 de abril de 2020. Disponível em: https://www.who.int/news/item/27-04-2020-who-timeline---covid-19. Acesso em: 25 jan.2021.

ZYLberberG, S. Morro da Providência: Memórias da Favella. Rio de Janeiro: Rio de Janeiro Prefeitura, Secr. Municipal de Cultura, Turismo e Esportes, 1992. 